\title{
Modification, Characterization, and Catalytic Application of Mesolite for One Pot Synthesis of 3-Methyl-4-arylmethylene-isoxazol-5(4H)-ones
}

\author{
Ganesh T. Pawar, Sachin P. Gadekar, Balasaheb R. Arbad, Machhindra K. Lande* \\ Department of Chemistry, Dr. Babasaheb Ambedkar Marathwada University, \\ Aurangabad (M.S.), 431004, India
}

Received: 25 th August 2016; Revised: 10 ${ }^{\text {th }}$ October 2016; Accepted: 17th October 2016

\begin{abstract}
Natural mesolite type zeolite was collected, modified by sulphuric acid treatment and characterized by using Powder-X ray diffraction, Scanning electron microscopy and Energy dispersive spectroscopy, Fourier transform infrared spectroscopy. Temperature programmed ammonia desorption, BrunauerEmmer-Teller surface area analysis. Modified dealuminated mesolite shows an efficient catalytic activity for one pot synthesis of 3-methyl-4-arylmethylene-isoxazol-5(4H)-ones derivatives, via one pot three component condensation of benzaldehyde, ethylacetoacetate and hydroxylamine hydrochloride. Present method offers several advantages over the reported methods like a simple and inexpensive modification of catalyst, mild reaction condition, easy separation of catalyst, simple work-up procedure, nonchromatographic isolation and purification desired product and excellent yield. Furthermore, catalyst could be reused without significant loose in activity. Copyright (C 2017 BCREC GROUP. All rights reserved
\end{abstract}

Keywords: 3-methyl-4-arylmethylene-isoxazol-5(4H)-ones; benzaldehyde; ethylacetoacetate; hyroxylaminehydrochloride; modification of mesolite; natural zeolite

How to Cite: Pawar, G.T., Gadekar, S.P., Arbad, B.R., Lande, M.K. (2017). Modification, Characterization, and Catalytic Application of Mesolite for One Pot Synthesis of 3-methyl-4-arylmethylene-isoxazol5(4H)-ones. Bulletin of Chemical Reaction Engineering \& Catalysis, 12 (1): $32-40$

(doi:10.9767/bcrec.12.1.655.32-40)

Permalink/DOI: http://dx.doi.org/10.9767/bcrec.12.1.655.32-40

\section{Introduction}

Nowadays, the development of green protocol for one pot synthesis of heterocyclic organic compound has gain much more attention in green chemistry. Most of the organic condensation, alkylation, acylation reaction are carried out using mineral acid/base and stoichiometric amount of Lewis acids like $\mathrm{AlCl}_{3}, \mathrm{BF}_{3}, \mathrm{ZnCl}_{2}$ [1]. Despite its high selectivity, these homogenous classical acid catalysts are inheriting dis-

* Corresponding Author.

E-mail: mkl_chem@yahoo.com

Telp.: +91 0240 2403311, Fax.: +91 02402403335 advantages like high toxicity, corrosive nature and generation of maximum waste, tedious recovery. Therefore, it is necessary to find sustainable alternatives to these hazardous catalysts by inexpensive, non toxic, reusable solid heterogonous catalyst. Accordingly, number heterogeneous solid acids such as nano mixed metal oxides supported clays, transition metal oxide doped mesoporous silica, zeolites are playing important role in organic synthesis in order to develop cleaner and eco friendly green process [2].

Zeolites are microporous, hydrated aluminosilicates minerals found naturally in the 
earth crust, containing polymeric three dimensional networks of $\left[\mathrm{AlO}_{4}\right]^{5-}$ and $\left[\mathrm{SiO}_{4}\right]^{4-}$ tetrahedron as primary building units. These unites are linked to each other by sharing oxygen atom, they also possesses channels and pore ranging in diameter $3-8 \AA$ and possess Lewis and Brönsted acidity in his framework [3]. Zeolites are obtained either from natural deposits or synthesized. Over 150 type of framework of synthetic zeolites have been reported and six different natural mineral of zeolite have been found in nature with substantial quantity and purity [4]. Natural zeolites are used as water softener, cation exchanger, adsorbent for heavy metal cations and dye molecules [5]. Natural zeolites are the good sensors for ammonia and carbon dioxide molecule [6]. Industrially natural zeolites are used as heterogeneous catalyst for alkylation, acylation, isomerization and petrochemical refining [7-10].

Mesolite is microporous fibrous natrolite type natural zeolite. General molecular formula of mesolite is $\left[\mathrm{Si}_{72} \mathrm{Al}_{48} \mathrm{O}_{240}\right.$ ] and NAT framework topology [11]. There are several modification methods to improve the acidity of zeolites such as hydrothermal treatment, acid/base leaching, $\mathrm{H}_{2} \mathrm{O}_{2}$ and microwave irradiation etc., among them dealumination of zeolite is useful tool to generate strong Lewis as well as Brönsted acidic sites in zeolite framework which can be achieved by acid treatment. The selective extraction of aluminium leads to formation of silianol nests and mesoporsity [12] in his framework (Scheme-1).

In recent years, isoxazoles derivates have received strong research interest because of their potent biological and pharmaceutical activity such antibacterial, antifungal, anticancer, anti-inflammatory activity [13-15]. Isoxaole derivatives are the building blocks of some natural products [16]. Besides these isoxaole motifs are important constituents of merocyanine dyes [17] and organic optical material [18]. Furthermore, isoxaole derivatives act as fluorescent chemosensor for fluoride aninon [19]. Hence by considering importance and applications of isoxaole derivatives several catalytic methods have been developed using homogenous and heterogeneous catalyst like potassium phthalimide [20], n-bromosuccinimide [21], sodium oxalate, tetra-butylammonium perchlorate, glycine [22], Tartaric acid [23], boric acid [24], DABCO [25], sodium benzoate [26], nano- $\mathrm{Fe}_{2} \mathrm{O}_{3}$ [27], and $\mathrm{H}_{3} \mathrm{PW}_{11} \mathrm{CuO}_{40}$ [28]. However, some of them suffered from some problems like harsh reaction condition, long reaction time, low yield and tedious work up for separation of catalyst which generate acidic effluent. Some methods required special conditions such as visible light [29] microwave [30] irradiations and refluxing reaction mixture in toxic homogenous Nitrogen containing organic bases like pyridine [31]. Hence in order to overcome these limitations it is necessary to develop simple, efficient and eco-friendly method for synthesis of 3-methyl4-arylmethylene-isoxazol-5(4H)-ones derivatives.

In continuation of our research work, on development of heterogeneous catalysts and their utilization for synthesis of heterocyclic organic compounds [32-33]. The present communication report collection, modification and catalytic application mesolite type zeolite sample which was collected from Aurangabad district of Marathwada region, Maharashtra state, India. It was modified by sulphuric acid treatment and characterized by X-ray diffraction, FT-IR, $\mathrm{NH}_{3}$-TPD, FT-IR, SEM-EDS, and BET and used as heterogeneous solid acid catalyst for one pot synthesis of 3-methyl-4arylmethylene-isoxazol-5(4H)-ones derivatives, (Scheme-2).

\section{Materials and Method}

\subsection{Chemicals and instruments}

All solvents and chemicals were analytical grade and purchased from Merck, Avra and Spectrochem chemicals and used as such. Melting points were taken in an open capillary and are uncorrected. FT-IR spectrum was recorded<smiles>C[Si](C)(C)O[Si](C)(C)O[Si](C)(C)O[Si](C)(C)O[Si](C)(C)O[Si](C)(C)O[Si](C)(C)O</smiles>

Scheme 1. Modification of mesolite by sulphuric acid treatment 
on Perkin Elmer; thin layer chromatography was performed on Merck pre-coated silica plates. ${ }^{1} \mathrm{H}$ NMR spectra were recorded on 400 $\mathrm{MHz}$ Bruker avance FT-NMR spectrometer in $\mathrm{CDCl}_{3}$ as solvent and chemical shifts values are recorded $\delta(\mathrm{ppm})$ relative to tetramethylsilane $\left(\mathrm{Me}_{4} \mathrm{Si}\right)$ as an internal standard. The X-ray diffraction patterns were recorded on Bruker 8-D advance X-ray diffractometer using monochromatic $\mathrm{Cu}-\mathrm{Ka}$ radiation $(\lambda=1.5405 \AA)$. Scanning electron microscope image with energy dispersive X-ray spectroscopy was obtained on JSM $6390 \mathrm{LV} 6330 \mathrm{LA}$ operated at $30.0 \mathrm{kV}$. The surface area was calculated by $\mathrm{N}_{2}$ adsorption performed on Quantachrome CHEMBET 3000 instrument. Temperature programmed ammonia desorption was recorded on micromeritice instrument from room temperature to $700{ }^{\circ} \mathrm{C}$ with heating rate $10^{\circ} \mathrm{C} / \mathrm{min}$.

\subsection{Modification of natural mesolite type zeolite}

Natural mesolite powder was washed and refluxed with distilled water for $3 \mathrm{~h}$ and dried in an oven at $150^{\circ} \mathrm{C}$ for $4 \mathrm{~h}$. The $5 \mathrm{~g}$ dried sample was mixed with $20 \mathrm{~mL}$ of $0.1 \mathrm{~N} \mathrm{H}_{2} \mathrm{SO}_{4}$. The resulting mixture was stirred continuously for $3 \mathrm{~h}$ and filtered by sintered glass crucible the product so obtained was washed with distilled water and dried in an oven at $110{ }^{\circ} \mathrm{C}$ for overnight. Finally, the resulting material was calcined in a muffle furnace (SONAR) at $500{ }^{\circ} \mathrm{C}$ for $5 \mathrm{~h}$ under air atmosphere. The sample were naturally cooled and further named as dealuminated mesolite.

2.3. Typical reaction procedure for the synthesis of 3-methyl-4-arylmethyleneisoxazol-5 (4H)-ones derivatives

A mixture of aromatic aldehyde (1 mmol), hydroxylamine hydrochloride (1 mmol), ethylacetoacetate $(1 \mathrm{mmol})$, and catalytic amount dealuminated mesolite ( $0.1 \mathrm{~g})$ was stirred in 20 $\mathrm{ml}$ of aqueous ethanol (EtOH: $\mathrm{H}_{2} \mathrm{O}$ of $\left.3: 1\right)$ solvent system for the time shown in Table 3 . The progress of the reaction was monitored by TLC (petroleum ether : ethyl acetate 7:3 as eluent). After completion of the reaction, the reaction solid crude product was dissolved in hot ethanol and filtered to recover catalyst the filtrate was concentrated under reduced pressure, and the crude product obtained was recrystallized from ethanol to afford pure product.

\subsection{Spectroscopic data a representative sample}

The spectroscopy data of the 4-(4methoxybenzylidene)-3-methylisoxazol-5-(4H)one (3b) yellow solid showed IR $(\mathrm{KBr}) 3449.25$, 3090.80 , 2979.37, 1730.73, 1589.49, 1552.20, 1425.08, $1265.23 \mathrm{~cm}^{-1},{ }^{1} \mathrm{H}$ NMR 2.279, (s $3 \mathrm{H}$, $\left.\mathrm{CH}_{3}\right), 3.918\left(\mathrm{~s}, 3 \mathrm{H}, \mathrm{OCH}_{3}\right)$ 7.00-7.023 (d, 2H), $7.341(\mathrm{~s}, 1 \mathrm{H}), 8.428-8.4517 .6(\mathrm{~d}, 2 \mathrm{H})$.

\section{Results and Discussion}

\subsection{X-ray diffraction (XRD)}

XRD patters of parent and dealuminated mesolite are given in Figure 1 shows intense peaks at $2 \theta^{\circ}=13.57,19.35,20.39,24.599$, $27.81,31.14,34.87,39.84$ with corresponding

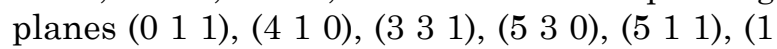
$92)$, (3 210$)$, (2 172 ), respectively, which are characteristic peaks of mesolite type natural zeolites [34]. The diffraction planes of dealumi-

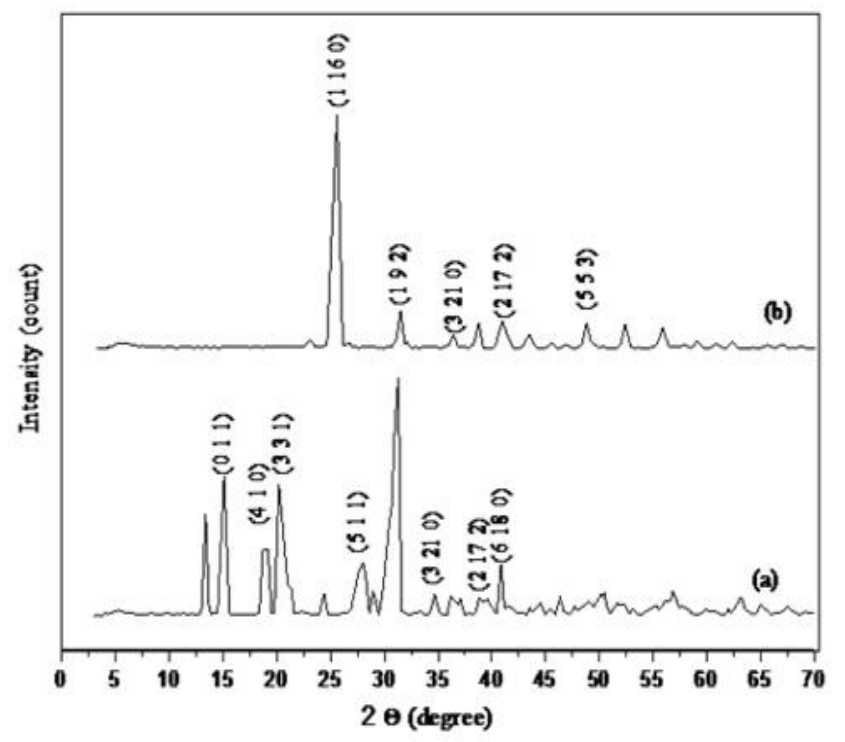

Figure 1. Powder XRD pattern of (a) parent natural mesolite (b) dealuminated mesolite<smiles>[R]c1ccc(/C=C2/C(=O)ON=C2C)cc1</smiles>

Scheme 2. Synthesis of 3-methyl-4-arylmethylene-isoxazol-5(4H)-ones derivatives 
nated mesolite shows low intensity due to loss of crytallinity and leaching of aluminum from framework, but both the samples are in orthorhombic phase.

\subsection{Scanning electron microscopy-energy dispersive spectrometry (SEM-EDS)}

Scanning electron microscopy and Energy Dispersive Spectroscopy has been extensively used to study surface morphology and elemental composition of catalytic material. The SEM image of parent and dealuminated mesolite is presented in Figures 2(a) and (b) shows rod shaped crystals. The SEM image of sample (b) shows small but less bulky crystals, this may be due to generation of mesoporsity because of acid leaching. The elemental composition of mesolite is shown in Figure 3 which show the presence of $\mathrm{O}, \mathrm{Al}, \mathrm{Si}, \mathrm{Ca}$, elements, with (atom \%) 38.47, 20.36, 28.19, 12.2, respectively. From EDS spectrum we have calculated empirical formula for parent mesolite is $\mathrm{Si}_{3} \mathrm{Al}_{2} \mathrm{Ca}_{1} \mathrm{O}_{4}$. The Figure 3(b) present EDS profile of dealuminated mesolite having elemental distribution in (atom \%) O, Al, Si of 38.47, 2.34, 59.19\% respectively, with corresponding empirical formula $\mathrm{Si}_{30} \mathrm{AlO}_{19}$. It has been found that $\mathrm{Si}: \mathrm{Al}$ ratio increases on acid treatment.

\subsection{Fourier transform infrared spectros- copy (FT-IR)}

FT-IR Spectroscopy is used to study the framework and structural building unites of zeolites. Figure 4 (a-c) shows the FT-IR spectra
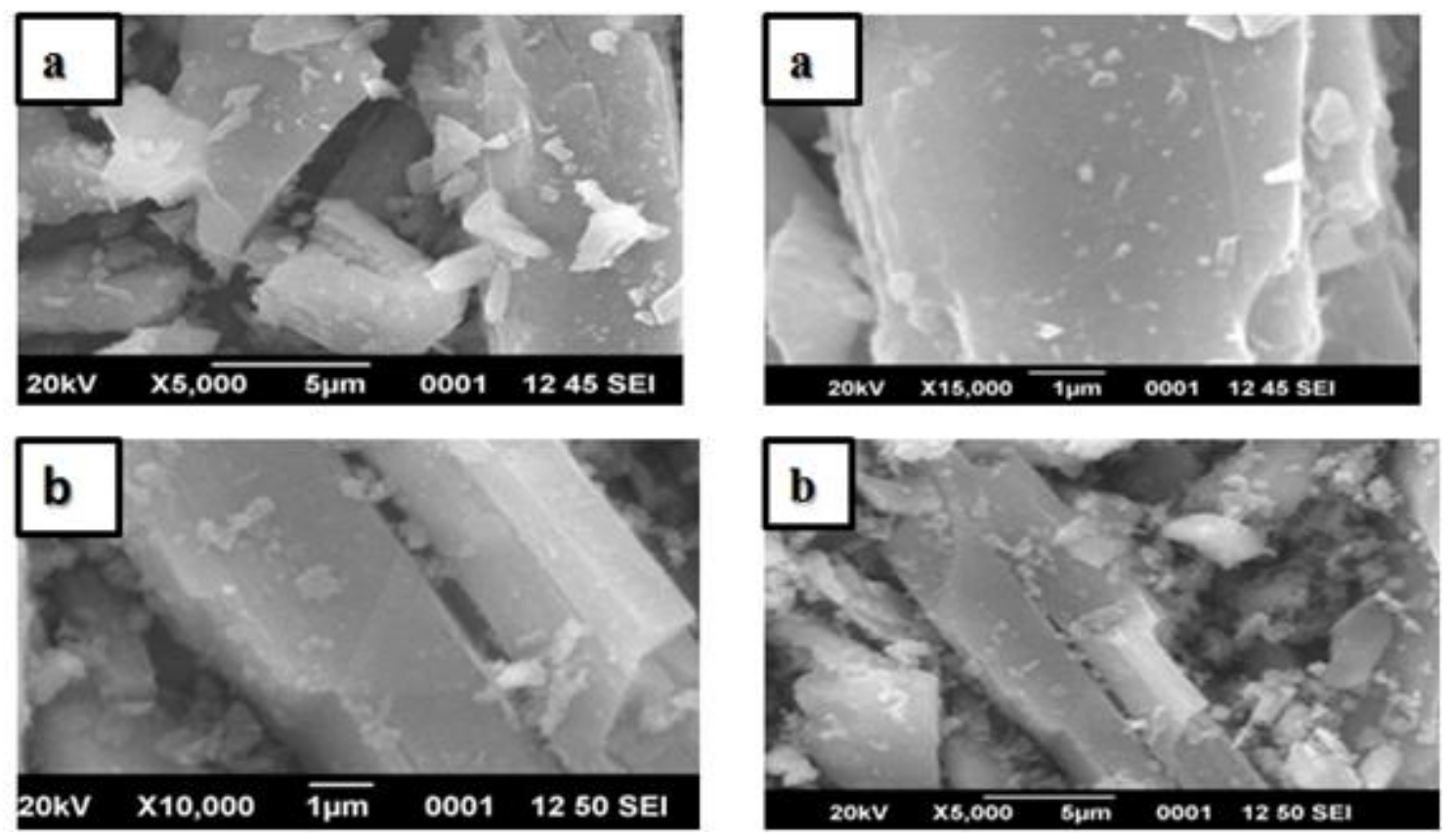

Figure 2. SEM-images of (a) parent natural Mesolite (b) dealuminated Mesolite.
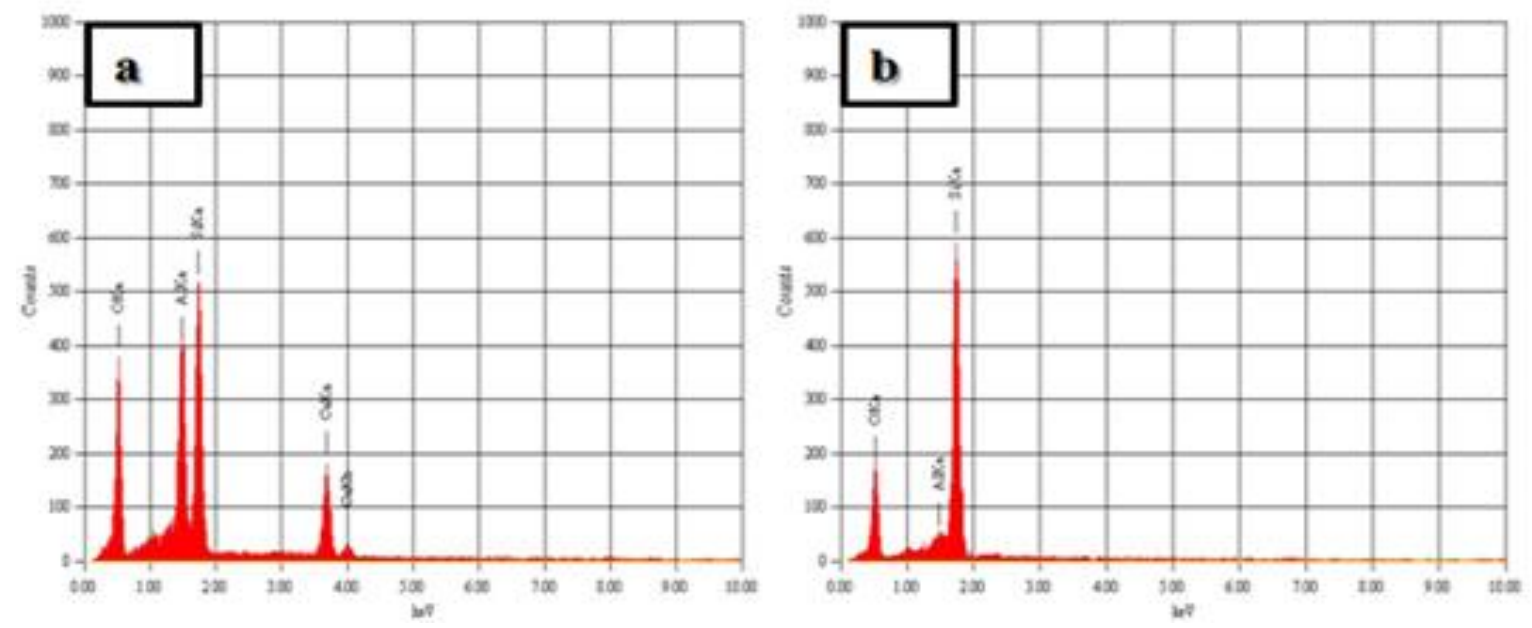

Figure 3. EDS-Spectrum of (a) parent mesolite (b) dealuminated mesolite 
of the mesolite. Figure 4(a) shows peak at 3756 $\mathrm{cm}^{-1}$ is due to the $\mathrm{Si}-\mathrm{OH}$ stretching vibration, $1689 \mathrm{~cm}^{-1}$ for the $\mathrm{Si}-\mathrm{OH}$ bending mode, and $965 \mathrm{~cm}^{-1}$ due to the $\mathrm{Si}-\mathrm{O}-\mathrm{Si}$ or $\mathrm{Al}-\mathrm{O}-\mathrm{Si}$ stretching vibration mode [35]. Figures 4(b) and 4(c) shows disappearance of band at 965 $\mathrm{cm}^{-1}$ this may be due to breaking of $\mathrm{Si}-\mathrm{O}-\mathrm{Si}$ or Al-O-Si framework and shows broad band between 3479-3756 $\mathrm{cm}^{-1}$ confirms presence of surface hydroxyl group [36].

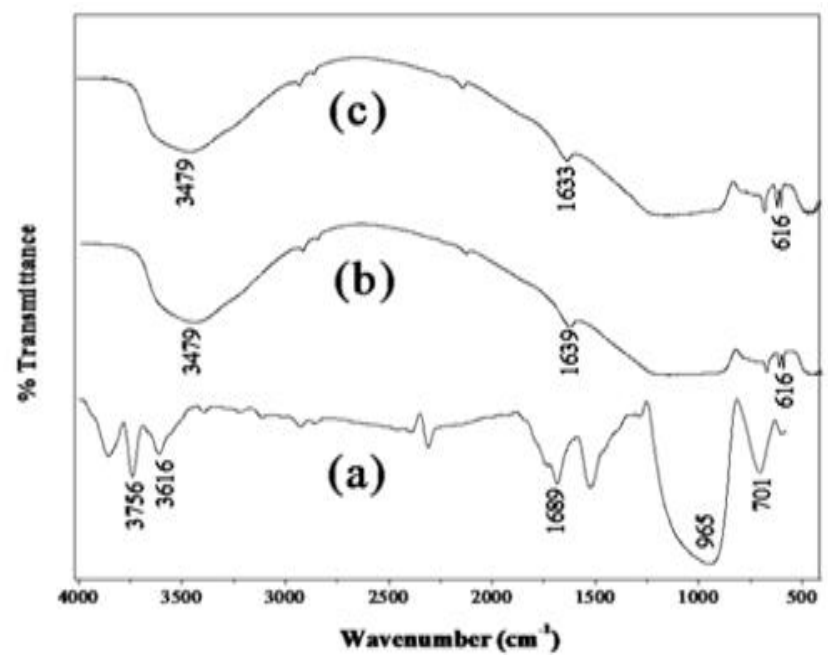

Figure 4. FT-IR spectrum of (a) parent mesolite, (b) calcined mesolite, (c) dealuminated mesolite.

\subsection{Temperature programmed ammonia desorption ( $\mathrm{NH}_{3}$-TPD)}

The Figure 5(a) and (b) shows $\mathrm{NH}_{3}$-TPD profile of parent and acid treated (dealuminated) mesolite. The Figure 5(a) shows two distinct peaks in the range 150-500 ${ }^{\circ} \mathrm{C}$ due to the presence of different types of acidic sites in the framework. The desorption peak observed at $196.2^{\circ} \mathrm{C}$ is due to presence of bridged hydroxyl group or Brönsted acidic sites. While peak observed at $420.9{ }^{\circ} \mathrm{C}$ is due desorption of $\mathrm{NH}_{3}$ from strong Lewis acidic sites. Figure $5(\mathrm{~b})$ shows single peak at $308.9^{\circ} \mathrm{C}$ is due to desorption of ammonia from Brönsted acidic sites [37]. From Table 1, the total acidity of parent mesolite and dealuminated mesolite is found 0.3724 and $0.5726 \mathrm{mmol} . \mathrm{g}^{-1}$ respectively. Therefore, acid treated mesolite shows more acidity than parent mesolite this may be due to increase in Lewis acidic sites because of dealumination. Surface area and porosity of catalyst were measured by Nitrogen adsorption desorption method. The BET surface area of dealuminated mesolite is found $4.486 \mathrm{~m}^{2} / \mathrm{g}$ which is greater than parent mesolite.

\subsection{Catalytic activity result}

In order to investigate optimum loading of catalyst and suitable solvent medium for present protocol $4-\mathrm{OCH}_{3}$ benzaldehyde $(1 \mathrm{mmol})$ were reacted with ethylacetoacetate $(1 \mathrm{mmol})$

Table 1. Acid strength and BET surface area of mesolite

\begin{tabular}{clcc}
\hline Sr. No. & \multicolumn{1}{c}{ Catalyst } & Total acidity mmol.g- ${ }^{-1}$ & BET surface area $\mathrm{m}^{2 / \mathrm{g}}$ \\
\hline 1 & Parent mesolite & 0.3724 & 0.1485 \\
2 & Dealuminated mesolite & 0.5726 & 4.4863 \\
\hline
\end{tabular}
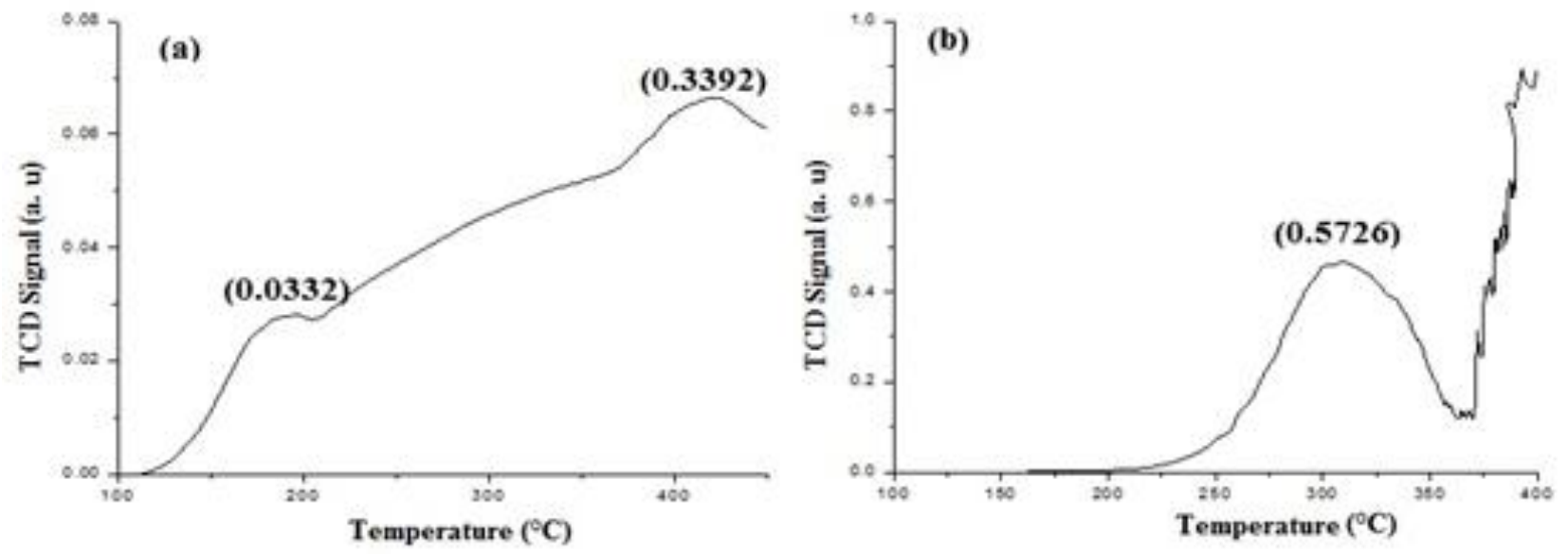

Figure 5. (a) $\mathrm{NH}_{3}$-TPD of parent mesolite (b) $\mathrm{NH}_{3}$-TPD of dealuminated mesolite 
and hydroxylamine hydrochloride $(1 \mathrm{mmol})$ as model reaction with different solvents and amount of dealuminated mesolite as catalyst at ambient condition (stirring) condition and results are summarized in (Table 2). In the absence of catalyst the reaction did not gave satisfactory yield of desired product (3b), which indicate important role of catalyst, $0.1 \mathrm{gm}$ of dealuminated mesolite is suitable to catalyze reaction smoothly. The same reaction was carried out under optimum loading of catalyst under different solvents, and it is observed that the no single solvent gave excellent yield of desired product, hence we have used mixture of $\mathrm{EtOH}$ and $\mathrm{H}_{2} \mathrm{O}(1: 1)$ as solvent for reaction, surprisingly reaction proceeds faster and maximum yield than other solvent system.

In order to explore the scope and importance of the present method different aromatic aldehydes were tested under optimum reaction con- ditions for synthesis of 3-methyl-4arylmethylene-isoxazol-5(4H)-ones derivatives (Table 3). The aldehydes with electron donating groups at para position such as $4-\mathrm{OCH}_{3}$, 4$\mathrm{CH}_{3}$, 4-OH, were react fast and give maximum yield in minimum time as compare to aldehydes having electron withdrawing group such as, 4-Cl which give tracer yield. After optimizing reaction conditions, efforts have been made towards the recovery and reusability of the catalyst. After completion of reaction solid product was dissolved in hot ethanol and filtered. The recovered catalyst was washed with acetone and activated by drying at $150{ }^{\circ} \mathrm{C}$ for 3 hour before the next catalytic run. The reusability of the catalyst was investigated for two times and it was found to retain almost consistent activity (Table 3, entry $3 b$ ).

To specify the advantages of proposed method, results of different reported methods

Table 2. Optimization of catalyst loading with different solvents for the synthesis of $3 a$

\begin{tabular}{clccc}
\hline Entry & \multicolumn{1}{c}{ Solvent } & $\begin{array}{c}\text { Catalyst } \\
\text { amount }(\mathrm{g})\end{array}$ & $\begin{array}{c}\text { Time } \\
(\mathrm{min})\end{array}$ & Yield(\%)a \\
\hline 1 & Ethanol & - & 120 & 33 \\
2 & Methanol & - & 120 & 30 \\
3 & Acetonitrile & - & 120 & 28 \\
4 & 1,4-dioxane & - & 120 & 27 \\
5 & Tetrahydrofuran & - & 120 & 25 \\
6 & Water & - & 120 & 53 \\
7 & Ethanol & 0.05 & 60 & 65 \\
8 & Ethanol & 0.1 & 60 & 67 \\
9 & Ethanol & 0.15 & 60 & 67 \\
10 & Ethanol & 0.2 & 60 & 68 \\
11 & Ethanol:Water $(3: 1)$ & 0.1 & 60 & 95 \\
12 & Ethanol:Water $(1: 3)$ & 0.1 & 60 & 85 \\
13 & Ethanol:Water $(1: 1)$ & 0.1 & 60 & 89 \\
\hline
\end{tabular}

aisolated yield

Table 4. Catalytic performance of different catalysts for the synthesis of 3-Methyl-4-arylmethyleneisoxazol-5(4H)-ones derivatives

\begin{tabular}{cllccc}
\hline \multirow{2}{*}{ Entry } & \multicolumn{1}{c}{ Catalyst } & \multicolumn{1}{c}{ Condition } & $\begin{array}{c}\text { Time } \\
(\mathrm{min})\end{array}$ & $\begin{array}{c}\text { Yield } \\
(\%)\end{array}$ & References \\
\hline 1 & Pottasium phthalimide & Water, R.T. & 70 & 96 & $(20)$ \\
2 & N-bromosuccinimide & Water, R.T. & 100 & 88 & $(21)$ \\
3 & Sodium oxalate & Water, R. T. & 70 & 90 & $(22)$ \\
4 & Tartaric acid & Water R.T. & 35 & 93 & $(23)$ \\
5 & Sodium tetraborate & Water R.T. & 50 & 90 & $(24)$ \\
6 & Pyridine & reflux in ethanol & 60 & 93 & $(31)$ \\
7 & Dealuminated mesolite & Starring in ethanol : wa- & 60 & 95 & Our results \\
\hline
\end{tabular}


Table 3. Dealuminated mesolite catalyzed cyclocondensation of aromatic aldehyde, elthylacetoacetate and hydroxylamine hydrochloride.

\begin{tabular}{|c|c|c|c|c|c|}
\hline \multirow{2}{*}{ Entry } & \multirow{2}{*}{ Aldehyde (R) } & \multirow{2}{*}{$\begin{array}{l}\text { Time } \\
(\mathrm{min})\end{array}$} & \multirow{2}{*}{ Yield $(\%)^{a}$} & \multicolumn{2}{|c|}{ M.P. $\left({ }^{\circ} \mathrm{C}\right)$} \\
\hline & & & & Observed & Literature \\
\hline 3a. & & 110 & 90 & 140 & $140-142^{21}$ \\
\hline $3 \mathrm{~b}$. & & 60 & $95(93,92,)^{c}$ & 174 & $175-177^{21}$ \\
\hline 3c. & & 60 & 93 & 211 & $210-211^{21}$ \\
\hline $3 \mathrm{~d}$ & & 120 & 85 & 198 & $199-201^{20}$ \\
\hline 3e. & & 130 & 80 & 190 & $189-2021^{20}$ \\
\hline $3 \mathrm{f}$ & & 120 & 88 & 212 & $213-215^{20}$ \\
\hline $3 g$ & I & 120 & 85 & 145 & $145-147^{29}$ \\
\hline $3 \mathrm{~h}$ & & 120 & Trace & -....- & $\cdots--$ \\
\hline $3 \mathrm{i}$ & & 100 & 90 & 220 & $220-221^{21}$ \\
\hline
\end{tabular}

Reaction conditions: benzaldehyde $(1 \mathrm{mmol})$, ethylacetoacetate $(1 \mathrm{mmol})$, hydroxyl aminehydrochloride (1 mmol), catalyst $0.1 \mathrm{~g}$, and ethanol : water $(1: 1) 15 \mathrm{~mL}$. a Isolated yields. cYield after consecutive cycle 
are compared with our results and are summarized in Table 4. It is found from tabulated results that, dealuminated mesolite promotes reaction more effectively under mild condition than other reported methods. Furthermore reported methods require additional workup to recover and reuse catalyst.

\section{Conclusions}

In summary, we have successfully modified natural mesolite zeolite by heat and $\mathrm{H}_{2} \mathrm{SO}_{4}$ treatments. Present modification method is simple and inexpensive. XRD and SEM-EDS analysis confirms the mesolite phase of natural zeolite. FT-IR, analysis identifies bridged and surface hydroxyl groups present in a zeolite. $\mathrm{NH}_{3}$-TPD analysis confirms presence of both weak and strong acidic sites in a natural zeolite. It has been found that the active sites and surface area was increased by $\mathrm{H}_{2} \mathrm{SO}_{4}$ treatment as compared to parent natural zeolite. The modified dealuminated mesolite is used as heterogeneous catalyst for the synthesis of 3methylarylmethylene-isoxazol-5(4H)-ones derivatives by condensation reaction between aldehyde, ethylacetoacetate and hydroxyl amine hydrochloride. Present method offers remarkable advantages such as non-toxic, noncorrosive and an inexpensive reaction conditions. Simple recovery and reusability of the catalyst make the reaction successful under environmental benign conditions.

\section{Acknowledgement}

We are grateful to the Head, Department of Chemistry, Dr. Babasaheb Ambedkar Marathwada University, Aurangabad-431004 (MS), India for providing the laboratory facility. The authors are thankful to STIC Cochin and IIT Madras for providing characterization facilities.

\section{References}

[1] Tundo, P., Anastas, P., Breen, J., Collins, T., Memoli, S., Miyamoto, J., Polyakoff, M., Tumas, W. (2000) Synthetic pathways and process in green chemistry. Pure Appl. Chem., 72: 1207-1228.

[2] Sheldon, R.A. (1997) Catalysis: Key to west minimization. J. Chem. Tech. Biotechnol., 68: 381-388.

[3] Breck, D.W. (1974). Zeolite Molecular Sieves, John Wiley, New York, 4.

[4] Baghbanian, S.M., Rezaei, N., Tashakkorin, H. (2013). Nanozeolite Clinoptilolite as a Highly Efficient Heterogeneous Catalyst for the Synthesis of Various 2-amino-4Hchromene Derivatives in Aqueous Media. Green Chem., 15: 3446-3450.

[5] Lopes, J.H., Nogueira, F.G., Goncalves, M., Oliveira, L.C. (2015). Modified Zeolites with Transition Metals $\mathrm{Cu}$ and Fe for Removal of Methylene Blue from Aqueous Medium: Mass Spectrometry Study. Bull. Chem. Reac. Eng. Catal., 10: 237-248.

[6] Wang, S., Zhu, Z.H. (2006). Ammonia Removal from Leachate Solution using Natural Chinese Clinoptilolite. J. Hazardous Material. 136: 946-995

[7] Smith, K., El-Hiti, G.A. (2011). Use of Zeolites for Greener and more Para-selective Electrophilic Aromatic Substitution Reactions. Green Chem., 13: 1579-1608.

[8] Sheemol, V.N., Tayagi, B., Jasara, R.V. (2004). Acylation of Toluene using Rare Earth Cation Exchanged Zeolite $B$ as Solid Acid Catalyst. J. Mol. Catal. A., 215: 201-208.

[9] Prochazkova, D., Kurfirtova, L., Pavlatova, J. (2012). Acylation of P-xylene over Zeolites. Catalysis Today. 179: 78-84.

[10] Kubicka, D., Kikthyanin, O. (2015) Opportunities for zeolites in biomass upgradingLessons from the refining and petrochemical industry. Catalysis Today, 243: 10-22.

[11] Gillet, P., Malezieux, J.M., Itie, J.P. (1996). Phase Changes and Amorphization of Zeolites at High Pressures: The Case of Scolecite and Mesolite. American Mineralogist. 81: 651-657.

[12] Valtchev, V., Majano, G., Mintova, S., Ramirez, J.P. (2013). Tailored Crystalline Microporous Materials by Post-synthesis Modification. Chemical Society Review. 42: 263-290.

[13] Shailaja, M., Manjula, A., Rao, B.V. (2011). Synthesis of Novel 3,5-disubstituted-4,5 trisubstituted Isoxazoles and their Biological Activity. Indian J. Chem., 50(B): 214-222.

[14] Bindu, P.J., Mahadenvan, K.M., Ravikuar Naik, T.R. (2012). An efficient one-pot synthesis and photoinduced DNA cleavage studies of 2-chloro-3-(5-aryl-4,5-dihydroisoxazol-3-yl) quinolines. Bio. Med. Chem. Lett., 22: 60956098.

[15] Silva, N.M., Tributino, J.L.M., Miranda, A.L. P., Barreiro, E.J., Carlos, A.M. (2002). New Isoazole Derivatives Designed as Nicotinic Acetylcholine Receptor Ligand Candidates. Eru. J. Med. Chem., 37: 163-170.

[16] Jin, Z. (2011). quinoline, quinazoline and acridione alkaloids. Nat. Prod. Rep., 28: 11431191.

[17] Zhang, X.H., Zhan, Y.H., Chen, D., Wang, F., Wang, L.Y. (2012). Merocyanine Dyes Containing an Isoazolone Nucleus: Synthesis, X- 
ray Crystal Structures, Spectroscopic Properties and DFT Studies. Dyes and Pigments. 93: 1408-1415.

[18] Zhang, X. H., Wang, L. Y., Zhan, Y. H., Fu. Y. E., Zai, G. H., Wen. Z. Y. (2011) Synthesis and structural studies of 4-[(5-methoxy-1H-indole3-yl)-methylene]-3-methyl-isoxazole-5-one by X-ray crystallography, NMR spectroscopy, and DFT calculation. J. Mol. Struct., 994: 371-378.

[19] Yang, Z., Zhang, K., Gong, F., Li, S., Chen, J., Ma, J.S., Sobenia, L.N., Mikhaleva, A.I., Yang, G., Trofirmov, B.A. (2011). A New Fluorescent Chemosensor for Fluoride Anion based on a Pyrrole-isoxazole Derivative. Beilstein J. Org. Chem., 7: 46-52.

[20] Kiyani, H., Ghorbani, F. (2013). Potassium Phthalimide as Efficient Basic Organocatalyst for the Synthesis of 3,4-disubstituted isoxazol-5(4H)-ones in Aqueous Medium. $J$. Soudi Chem. Soc., Article In Press (doi: 10.1016/j.jscs.2013.11.002)

[21] Kiyani, H., Kannani, A., Ajloo, D., Ghorbani, F., Vakili, M. Bromosuccinimide (NBS)promoted, three-component synthesis of a,bunsaturated isoxazol-5(4H)-ones, and spectroscopic investigation and computational study of 3-methyl-4-(thiophen-2-ylmethylene) isoxazol-5(4H)-one. Res. Chem. Intermed. doi 10.1007/s11164-014-1857-5.

[22] Kiyani, H., Jabbari, M., Mosallanezhad, A. (2014). Efficient Three Component Synthesis of 3,4-disubstitutedisoxazol-5(4H)-ones in Green Media, Jordan J. Chem. 9(4): 279-288.

[23] Khandebharad, A.U., Gill, C.H., Agrawal, B.R. (2015). Synthesis of 3-Methyl-4arylmethylene-isoxazol-5(4H)-ones Catalyzed by Tartaric Acid in Aqueous Media. Res. J. Chem. Sci. 5(5): 27-32.

[24] Kiyani, H., Ghorbani, F. (2013). Synthesis of Arylmethylidene-isoxazol-5(4H)-ones via Three-Component Reaction in Water Catalyzed by Sodium Tetraborate. Open. J. Org. Chem. 1: 9-15.

[25] Mirzazadeh, M., Mahadavina, G.H. (2012). Fast and Efficient Synthesis of 4-Arylidene-3phenylisoxazol-5-ones E-J. Chem., 9(1): 425429.

[26] Liu, Q., Zhang, Ya-Nan (2011). One-pot Synthesis of 3-Methyl-4-arylmethylene-isoxazol$5(4 \mathrm{H})$-ones catalyzed by Sodium Benzoate in Aqueous Media: A Green Chemistry Strategy. Bull. Korean Chem. Soc. 32(10): 3559-3560.

[27] Fozooni, S., Hosserinzadeh, N.G., Hamidian, H., Akhgar, M.R. (2013). Nano $\mathrm{Fe}_{2} \mathrm{O}_{3}$, Clinoptilolite and $\mathrm{H}_{3} \mathrm{PW}_{12} \mathrm{O}_{40}$ as Efficient Catalysts for Solvent-Free Synthesis of $5(4 \mathrm{H})$ - I s o x a zolone under Microwave Irradiation Conditions. J. Braz. Chem. Soc., 24(10): 1649-1655.
[28] Heravi, M.M., Derikvand, F., Haeri, A., Oskooie, A.H., Bamoharram, F.F. (2008). Heteropolyacids as Green and Reusable Catalysts for the Synthesis of Isoxazole Derivatives. Synth. Commun., 38(1): 135-140.

[29] Saikh, F., Das, J., Ghosh, S. (2013). Synthesis of 3-Methyl-4-arylmethylene Isoxazole-5(4H)ones by Visible Light in Aqueous Ethanol. Tetrahedron Lett., 54: 4679-4682.

[30] Rajanarendar, E., Rao, E.K., Karunakr, D., (2006). Microwave Assisted Rapid and Efficient Synthesis of 2,1-Benzoisoxazoles. Indian J. Chem., 45(B): 805-807.

[31] Ablajan, K., Xiamuxi, H. (2011). The Convenient Synthesis of 4-Arylmethylidene-4, 5Dihydro-3-phenylisoxazol-5-ones. Chin. Chem. Lett., 22: 151-154.

[32] Magar, R.R., Pawar, G.T., Arbad, B.R. Lande, M.K. (2016). Fe-MCM-22: An Efficient Solid acid Catalyst for One Pot Four Component Synthesis of $1 \mathrm{H}$-pyrazolo [1,2-b] phthalazine5, 10-dione derivatives. Adv. Org. Chem. Lett., 3(1): 8-14

[33] Pawar, G.T., Magar, R.R., Lande, M.K. (2016). Mesolite Catalyzed One Pot Synthesis of Quinoline-3-0carboniotrile Derivatives. Iranian J. Catal., 6: 355-362

[34] Treacy, M.M.J., Higgins, J.B. Collection of simulated XRD powder patterns for zeolite.

[35] Kondo, J.N., Nishitani, R., Yoda, E., Yokoi, T., Tatsumi, T., Domen, K. (2010). A Comparative IR Characterization of Acidic Sites on $\mathrm{HY}$ Zeolite by Pyridine and $\mathrm{CO}_{2}$ Probes with Silica-alumina and c-Alumina References. Phy. Chem., 12:11576-1158.

[36] Poh, E., Poh, H., Nur, Muhid, M.N.M., Hamdan, H. (2006). Sulphated AlMCM-41: Mesoporous Solid Brönsted Acid Catalyst for Dibenzoylation of Biphenyl. Catal. Today, 114: 257-262

[37] Rathod, S.B., Gambhire, AB., Arbad, B.R., Lande, M.K. (2010). Synthesis, Characterization and Catalytic Activity of $\mathrm{Ce}_{1} \mathrm{Mg}_{\mathrm{x}} \mathrm{Zr}_{1-\mathrm{x}} \mathrm{O}_{2}$ (CMZO) Solid Heterogeneous Catalyst for the Synthesis of 5-Arylindne Barbituric Acid Derivatives. Bull. Korean Chem. Soci., 31: 339343.

[38] Narayan, S., Viaya, J.J., Sivasanker, S., Alam, M., Tamizhdurai, P., Kennedy, L.J. (2015). Characterization and Catalytic Reactivity of Mordenite-investigation of Selective Oxidation of Benzyl Alcohol. Polyhedron, 89: 289-296. 